\title{
Heat Shock Protein 72 Enhances Autophagy as a Protective Mechanism in Lipopolysaccharide- Induced Peritonitis in Rats
}

\author{
Shu Li, ${ }^{*}$ Yi Zhou, ${ }^{*}$ Jinjin Fan, ${ }^{*}$ Shirong Cao, ${ }^{*}$ \\ Tao Cao, ${ }^{*}$ Fengxian Huang, ${ }^{*}$ Shougang Zhuang, ${ }^{\dagger}$ \\ Yihan Wang, ${ }^{\ddagger \S}$ Xueqing $\mathrm{Yu},{ }^{*}$ and Haiping Mao* \\ From the Department of Nephrology,* the First Affiliated Hospital, \\ Sun Yat-sen University, Guangzhou, China; the Department of \\ Medicine, ${ }^{\dagger}$ Brown University School of Medicine, Providence, \\ Rhode Island; Nephropathology Associates, ${ }^{\ddagger}$ Little Rock, Arkansas; \\ and the Laboratory for Kidney Pathology, Inc., ${ }^{\$}$ Nashville, \\ Tennessee
}

Peritoneal dialysis-related peritonitis causes the denudation of mesothelial cells and, ultimately, membrane integrity alterations and peritoneal dysfunction. Because heat shock protein 72 (HSP72) confers protection against apoptosis and because autophagy mediates survival in response to cellular stresses, we examined whether autophagy contributes to HSP72mediated cytoprotection in lipopolysaccharide (LPS)induced peritonitis. Exposure of cultured peritoneal mesothelial cells to LPS resulted first in autophagy and later, apoptosis. Inhibition of autophagy by 3-methyladenine or Beclin-1 small-interfering RNA sensitized cells to apoptosis and abolished the antiapoptotic effect of HSP72, suggesting that autophagy activation acts as a prosurvival mechanism. Overexpression of HSP72 augmented autophagy through cJun N-terminal kinase (JNK) phosphorylation and Beclin-1 up-regulation. Suppression of JNK activity reversed HSP72-mediated Beclin-1 up-regulation and autophagy, indicating that HSP72-mediated autophagy is JNK dependent. In a rat model of LPSassociated peritonitis, autophagy occurred before apoptosis in peritoneum. Up-regulation of HSP72 by geranylgeranylacetone increased autophagy, inhibited apoptosis, and attenuated peritoneal injury, and these effects were blunted by down-regulation of HSP72 with quercetin. Additionally, blocking autophagy by chloroquine promoted apoptosis and aggravated LPSassociated peritoneal dysfunction. Thus, HSP72 protects peritoneum from LPS-induced mesothelial cells injury, at least in part by enhancing JNK activation-dependent autophagy and inhibiting apoptosis. These findings imply that HSP72 induction might be a potential therapy for peritonitis. (Am J Pathol 2011, 179:2822-2834; DOI: 10.1016/j.ajpath.2011.08.013)

Peritoneal dialysis (PD) has become a major mode of therapy for patients with end-stage renal failure. Unfortunately, peritonitis often results in these patients from this procedure. Mesothelial cells are critical components in maintaining the integrity and functional properties of the peritoneum. Lipopolysaccharide (LPS) released from organisms is a potent mediator for triggering the injury of the peritoneum, which results in mesothelial cell death and ultrafiltration failure in PD patients. Animal models of septic shock indicate that apoptosis contributes to primary organ damage. Moreover, LPS may directly cause apoptotic cell death in a variety of organs, including kidney, lung, intestine, liver, and heart. ${ }^{1-5}$ Recent studies have demonstrated that LPS can also trigger autophagy in multiple disease states, ${ }^{6-8}$ and up-regulation of LPSinduced autophagy protects cells from apoptotic cell death through elevating the apoptotic threshold. ${ }^{6,9}$ However, the direct effects of LPS on both apoptosis and autophagy of peritoneal mesothelial cells are unknown.

Macroautophagy (generally referred to as autophagy) is a ubiquitous, genetically programmed, and evolutionarily conserved process, characterized by the formation and accumulation of double- or multiple-membrane cytoplasmic vesicles known as autophagosomes, which fuse with lysosomes to form autophagolysosomes. ${ }^{10}$ This process is initiated by induction of several autophagy genes including those that express microtubule-associ-

Supported by grants from the National Natural Science Foundation of China (81070553) and Guangdong Natural Science Foundation of China (10251008901000003).

Accepted for publication August 24, 2011.

S.L. and Y.Z. contributed equally to this work.

Address reprint requests to Haiping Mao, M.D., Ph.D., Department of Nephrology, the First Affiliated Hospital, Sun Yat-sen University, 58 Zhongshan Road II, Guangzhou, China, 510080. E-mail: maohp@mail. sysu.edu.cn. 
ated protein light chain 3 (LC3), Beclin-1, and other autophagy-related (ATG) proteins. ${ }^{11,12}$ LC3 is known to exist on autophagosome membrane and serves as a specific marker of autophagy. Under baseline conditions, autophagy is a physiological cellular mechanism for the turnover of long-lived cytoplasmic proteins and elimination of damaged organelles to maintain cell homeostasis. In response to cellular stress, autophagy may promote cell survival by inhibiting apoptosis, ${ }^{13-15}$ because blocking autophagy, either pharmacologically or genetically, leads to rapid cell death. ${ }^{16,17}$ Furthermore, autophagy plays a protective role in some diseases such as renal ischemia/reperfusion, cancer, and infections. ${ }^{18-20}$

Heat shock protein 72 (HSP72) is a prominent stress protein. As a molecular chaperone, it exerts cytoprotective effects in protein folding, transport, and degradation. HSP72 also participates in preventing apoptosis through several distinct mechanisms: blocking of cytochrome $c$ release from mitochondria, ${ }^{21}$ inhibition of apoptosome formation, ${ }^{22}$ and phosphorylation of $\mathrm{JNK}^{23}$ Indeed, HSP72 confers protection by inhibiting peritoneal dialysis fluid-induced intracellular reactive oxygen species accumulation in mesothelial cells. ${ }^{24}$ However, it has not been elucidated whether autophagy serves as a mechanism for HSP72-mediated protection in peritoneal mesothelial cells or tissue.

In this study, we examined the biological function of autophagy in LPS-induced apoptosis using human peritoneal mesothelial cell line (HMrSV5) and primary cultured peritoneal mesothelial cells and peritonitis in rats. We also determined whether HSP72 could inhibit LPSinduced apoptosis and promote cell survival via activation of autophagy. Furthermore, we investigated the underlying molecular mechanism by which HSP72 regulates the autophagy pathway.

\section{Materials and Methods}

\section{Materials}

Reagents were obtained from the following sources: LPS (Escherichia Coli 0111:B4), 3-methyladenine (3-MA), ammonium chloride $\left(\mathrm{NH}_{4} \mathrm{Cl}\right)$, SP600125, chloroquine (CQ), and quercetin $(\mathrm{Q})$ were from Sigma-Aldrich (St. Louis, $\mathrm{MO}$ ). Geranylgeranylacetone (GGA) was purchased from Eisai China Inc. (Shanghai, China). Anti-Beclin-1, antiAtg5, anti-Atg12, anti-LC3, anti-phospho-SAPK/JNK (Thr183/Tyr185), anti-SAPK/JNK, anti-caspase 3, and anti-Bcl-2 were from Cell Signaling Technology (Danvers, MA). Anti-HSP72 was from Stressgen Biotechnologies (Victoria, BC, Canada). Anti-cytokeratin 18 was from Sigma-Aldrich (St. Louis, MO). Vimentin was from Boster Biological Technology (Wuhan, China). Horseradish peroxidase-conjugated anti-mouse IgG, horseradish peroxidase-conjugated anti-rabbit IgG, Alexa Fluro 546-conjugated anti-rabbit IgG, and Alexa Fluro 546-conjugated anti-mouse IgG were from Cell Signaling Technology. Lipofectamine LTX and Plus Reagent were from Invitrogen Life Technologies (Paisley, UK). The green fluorescent protein (GFP)-LC3 fusion plasmid was designed by
Guangzhou FulenGen Co., Ltd (Guangzhou, China). Beclin-1-specific small-interfering RNA (siRNA) (sense, 5'CUCAGGAGAGGAGCCAUUUTT-3'; antisense, 5'-AAAUGGCUCCUCUCCUGAGTT-3') and control scrambled siRNA (sense, 5'-UUUAGCCGAUACUGCCUAGTT-3'; antisense, 5'CUAGGCAGUAUCGGCUAAATT-3'); JNK1/2-specific siRNA (sense, 5'-AAAGAAUGUCCUACCUUCUTT-3'; antisense, 5'AGAAGGUAGACAUUCUUUTT-3'); and control scrambled siRNA (sense, 5'-UUCUCCGAACGUGUCACGUTT-3'; antisense, 5'-ACGUGACACGUUCGGAGAATT-3') were from Shanghai GenePharma Co., Ltd (Shanghai, China). Adenoviruses containing HSP72 cDNA (Adv-HSP72) were kindly provided by Dr. Steven Borkan (Boston Medical Center, Boston University, Boston, MA). HSP72 plasmid and HSP72-specific siRNA were generated as reported previously. ${ }^{25,26}$

\section{Human Peritoneal Cell Line Culture and Viability}

The in vitro studies were performed in human peritoneal mesothelial cell line (HMrSV5), which was kindly provided by Dr. Jian Yao (Department of Nephrology, Shanghai First People's Hospital, Shanghai, China). This cell line was originally established and well documented by Dr. Pierre Ronco (Department of Nephrology, Tenon Hospital, Paris, France) after infection of a fully characterized primary culture of human peritoneal mesothelial cells with a large, T-antigen-encoding retroviral vector. ${ }^{27} \mathrm{HMrSV} 5$ cells were cultured in DMEM Nutrient Mix F12 medium (Invitrogen Life Technologies, Carlsbad, CA) supplemented with $10 \%$ fetal bovine serum and antibiotics in a $37^{\circ} \mathrm{C}$ incubator with $5 \% \mathrm{CO}_{2}$. Experiments were performed at approximately $70 \%$ to $80 \%$ confluence cultures after 24 hours of serum deprivation. Cell viability was determined by the MTT [3-(4, 5-dimethylthiazol-2-yl)-2, 5-diphenyl tetrazolium bromide] test.

\section{Isolation and Culture of Human Peritoneal Mesothelial Cells}

The study was approved by the human ethics committees of Sun Yat-sen University (Guangzhou, China). Specimens of normal human omentum were obtained from an elective abdominal surgical procedure with the informed consent of patients. Human peritoneal mesothelial cells (HPMCs) were isolated as previously reported. ${ }^{28}$ In brief, omental tissue was washed in sterile phosphate buffered saline (PBS) three times and then digested with $0.1 \%$ trypsin $/ 0.02 \%$ EDTA for 30 minutes at $37^{\circ} \mathrm{C}$ with continuous rotation. The suspension was then centrifuged at $1500 \mathrm{rpm}$ for 10 minutes at $4^{\circ} \mathrm{C}$. The cell pellet was washed twice in RPMI 1640 (Sigma-Aldrich, St. Louis, MO) and cultured in $75-\mathrm{cm}^{2}$ flasks with RPMI 1640, $20 \%$ fetal calf serum, penicillin ( $100 \mathrm{U} / \mathrm{mL})$, streptomycin $(100 \mu \mathrm{g} / \mathrm{mL})$, and insulin $(30 \mu \mathrm{g} / \mathrm{mL})$ at $37^{\circ} \mathrm{C}, 5 \% \mathrm{CO}_{2}$ incubator. HPMCs were characterized by the typical cobblestone appearance at confluence, the presence of vimentin and cytokeratin 18, and the absence of factor VIII-related antigen by the immunofluorescent technique. 
HPMCs between passages 1 and 3 were used for all experiments.

\section{Isolation and Culture of Rat Peritoneal Mesothelial Cells}

Rat peritoneal mesothelial cells (RPMCs) were isolated and cultured according to the method described in our previous reports. ${ }^{29,30}$ Briefly, RPMCs were prepared by intraperitoneal injection with a $0.25 \%$ trypsin/0.02\% EDTA solution for 20 minutes. To harvest RPMCs, cellular components were centrifuged at 1500 rpm for 10 minutes, washed with D-Hanks' balanced salt solution, and then resuspended in DMEM/F12 medium supplemented with $15 \%$ fetal calf serum, penicillin $(100 \mathrm{U} / \mathrm{mL})$, and streptomycin $(100 \mu \mathrm{g} / \mathrm{mL})$. Cells were seeded into $75-\mathrm{cm}^{2}$ plastic flasks and incubated at $37^{\circ} \mathrm{C}$ in a humidified $5 \% \mathrm{CO}_{2}$ atmosphere. The characteristics of mesothelial cells were examined as described above. Cells were studied between passages 2 and 4 .

\section{Induction of Autophagy/Apoptosis in Vitro}

To induce autophagy/apoptosis, cells were incubated with LPS at various concentrations (approximately 1 to 10 $\mu \mathrm{g} / \mathrm{mL}$ ) for the period of time as indicated (approximately 0 to 72 hours). In the initial studies, we determined the ideal exposure time and concentration of LPS based on cell viability in HMrSV5 by the MTT assay. Autophagy inhibitors, 3-MA (10 mmol/L), $\mathrm{NH}_{4} \mathrm{Cl}(10 \mathrm{mmol} / \mathrm{L})$, or Beclin-1 siRNA (100 nmol/L), were directly added to the culture before cells were exposed to LPS.

\section{Apoptosis Assays}

Apoptosis in cultured cells was assessed by flow cytometry using an Annexin V-FITC Apoptosis Detection Kit (Sigma) according to the manufacturer's protocol. Briefly, cells(approximately $5 \times 10^{5}$ cells per assay) were trypsinized, collected by centrifugation at $1000 \times g$ for 5 minutes, and incubated for 10 minutes at $37^{\circ}$ with Annexin V-FITC. Propidium iodide ( $1 \mu \mathrm{g} / \mathrm{mL}$ ) was added before flow cytometric analysis [fluorescence-activated cell sorting (FACS)]. Cells $(10,000)$ were recorded in each analysis. FACS data were used to determine the percentage of cells that were undergoing apoptosis.

Apoptosis in histological sections was identified by terminal deoxynucleotidyl transferase dUTP nick-end labeling (TUNEL) assay using an in situ cell death detection kit (Promega) following the manufacturer's instructions as described in our previous work. ${ }^{31}$ Briefly, paraffin-embedded peritoneal tissue sections were deparaffinized and permeabilized with $20 \mu \mathrm{g} / \mathrm{mL}$ proteinase $\mathrm{K}$ for 20 minutes at room temperature. The sections were then exposed to a TUNEL reaction mixture containing terminal deoxynucleotidyl transferase for 1-hour incubation at $37^{\circ} \mathrm{C}$ in a humidified atmosphere. Positive staining was identified in the cell nucleus with DNA fragmentation under confocal microscopy. For quantification, 10 representative fields were selected from each tissue section, and the amount of TUNEL-positive cells per $100 \mathrm{~mm}^{2}$ was evaluated.

\section{Western Blotting Analysis}

Cells or rat peritoneum were lysed in $150 \mathrm{mmol} / \mathrm{L} \mathrm{NaCl}$, $10 \mathrm{mmol} / \mathrm{L}$ Tris- $\mathrm{HCl}, 5 \mathrm{mmol} / \mathrm{L}$ EDTA, $1 \mathrm{mmol} / \mathrm{L}$ EGTA, and $1 \%$ Triton $\mathrm{X}-100$ with a protease inhibitor cocktail (Cell Signaling Technology), sonicated three times for 10 seconds per time, resolved by SDS-PAGE, processed for immunoblotting with specific antibodies, and detected using an enhanced chemiluminescence system as previous described. ${ }^{25}$ Densitometric quantification was performed with the image analysis program (FluorChem 8900; Alpha Innotech Corp, San Leandro, CA).

\section{Immunohistochemical and Immunofluorescent Analysis}

All immunostainings were performed on $2-\mu \mathrm{m}$ paraffinembedded parietal peritoneal sections, as previously described. ${ }^{31}$ In immunohistochemical staining, a primary antibody to HSP72 was used, followed by the DAKO EnVision horseradish peroxidase kit (DAKO, Carpinteria, CA). Negative controls were performed with nonimmune mouse serum substituted for the specific primary antibodies.

For immunofluorescent analysis, cells were seeded onto glass coverslips, exposed to different experiment conditions, and fixed in 4\% PBS-buffered paraformaldehyde. Formation of autophagic vesicles was monitored by transient expression of punctate GFP-LC3 aggregation in cells. To quantify the percentage of HMrSV5 cells with LC3 dots, at least 200 cells per condition were counted in 20 different, randomly selected fields. Only cells with four or more prominent dots of LC3 were scored. To detect HSP72, Beclin-1, and LC3, cells or $5-\mu \mathrm{m}$ paraffin-embedded parietal peritoneal sections from rats were incubated with the indicated antibodies followed by Alexa Fluro 546-conjugated anti-mouse IgG or Alexa Fluro 546-conjugated anti-rabbit IgG. Peritoneal mesothelial cells in peritoneum were identified by staining with anti-cytokeratin 18. DAPI (Sigma-Aldrich) was used to stain the nucleus. All images were collected by a laser scanning confocal microscopy (Zeiss LSM 510 META; Carl Zeiss, Oberkochen, Germany).

\section{Transmission Electron Microscopy}

Peritoneal tissues were fixed at room temperature with $2.5 \%$ glutaraldehyde, $2 \%$ paraformaldehyde, $0.1 \mathrm{~mol} / \mathrm{L}$ PBS (pH 7.3). The samples were then postfixed in $1 \%$ osmium tetroxide, en bloc stained with 1\% uranyl acetate, dehydrated through a graded series of ethanol, and embedded in LX-112 medium. Ultrathin sections were cut in a Leica Ultra-cut Microtome (Leica, Deerfield, IL), stained with $2 \%$ uranyl acetate and lead citrate, and examined using a JEM 1010 transmission electron microscope (JEOL, USA, Inc., Peabody, MA). Digital images were 
obtained using the AMT Imaging System (Advanced Microscopy Techniques Corp., Danvers, MA).

\section{Animal Studies}

Male Sprague-Dawley rats (200 to $250 \mathrm{~g}$ ) were obtained from Guangdong Medical Experimental Animal Center (Guangzhou, China). The animal experimental protocols were approved by the Animal Care and Use Committee of the Sun Yat-sen University. Acute peritonitis was induced in rats by intraperitoneal injection of a single dose of LPS $(1 \mathrm{mg} / \mathrm{kg})$ in $1 \mathrm{~mL}$ of sterile saline. ${ }^{32,33}$ A total of $400 \mathrm{mg} / \mathrm{kg}$ GGA was given orally to rats to induce HSP72 overexpression as described previously. ${ }^{31}$ For GGA/ quercetin combination treatment, rats were injected intraperitoneally with quercetin $(100 \mathrm{mg} / \mathrm{kg} / \mathrm{rat}) 1$ hour before GGA treatment. ${ }^{34}$ To test the effects of autophagy inhibitor $C Q$ on peritoneal injury, rats were given $60 \mathrm{mg} / \mathrm{kg} \mathrm{CQ}$ by intraperitoneal injection 1 hour before LPS administration. ${ }^{18}$ Control rats received only sterile saline. The rats ( $n=5$ each) were sacrificed at $0,4,8,12,24$, and 48 hours after peritonitis, respectively. Both parietal and visceral peritoneum was collected and frozen in liquid nitrogen. For the histological study, the tissue was fixed in formalin, dehydrated, and then paraffin embedded using standard techniques and subjected to the studies described above.

\section{Peritoneal Function Tests}

Peritoneal membrane function was evaluated by a 4-hour peritoneal equilibration test (PET) as previously described. ${ }^{29}$ PET was performed in all rats at 0 hours and again after 48 hours peritonitis. At each PET, $25 \mathrm{~mL}$ of conventional peritoneal dialysate fluid containing $4.25 \%$ glucose (Baxter Health Care, Guangzhou, China) was infused into the peritoneal cavity of rats. Under ether anesthesia, blood samples were taken from the tail vein at the beginning and at the end of the PET. Dialysate samples were collected at 0 and 4 hours of the dialysate dwell for urea nitrogen and glucose, and the volume was recorded. Peritoneal membrane function was quantitated by the dialysate to plasma ratio D/P of urea nitrogen and $D / D_{0}$ of glucose, where $D$ is the glucose concentration in the dialysate after 4-hour dwell, and $D_{0}$ is glucose concentration in the dialysis solution before instillation into the peritoneal cavity. Leukocyte counts were quantitatively assessed on $1 \mathrm{~mL}$ of dialysate effluents by an automatic hematology analyzer.

\section{Statistical Analysis}

The data are expressed as mean \pm SE for at least three independent experiments. Statistical analysis was performed by analysis of variance with a post hoc analysis using the Student-Newman-Keuls test. All calculations were performed using the standard statistical software SPSS 13.0 (Armonk, NY). $P<0.05$ was considered as significant.

\section{Results}

\section{LPS-Induced Autophagy Precedes Apoptosis in Peritoneal Mesothelial Cells in Vitro}

Increasing evidence suggests a link between autophagy and apoptosis. ${ }^{35,36}$ As a first step toward understanding the role of autophagy in apoptosis of mesothelial cells, we examined the effect of LPS on autophagy in HMrSV5. A critical step in the autophagic process is the ligation of LC3 to phosphatidylethanolamine, resulting in aggregates of LC3. ${ }^{37,38}$ To visualize processes related to autophagy, cells were transiently transfected with GFP-LC3 fusion plasmid followed by exposure to $1 \mu \mathrm{g} / \mathrm{mL}$ of LPS for 48 hours. Confocal microscopy was used to trace the redistribution of LC3 during autophagosome formation. As shown in Figure 1A, GFP-LC3 was found predominantly as diffuse green fluorescence in the cytoplasm in control cells. A characteristic punctate fluorescent pattern was observed in LPS-treated cells, indicating the recruitment of GFP-LC3 during autophagosome formation. Furthermore, the accumulation of autolysosomes was blocked by the addition of 3-MA, a pharmacological inhibitor of autophagy.

An increase in GFP-LC3 accumulation can be associated with either enhanced formation of autophagosomes or impaired autophagosome degradation. To distinguish these two possibilities, punctate GFP-LC3 was assessed in the presence or absence of $\mathrm{NH}_{4} \mathrm{Cl}$, which interferes with the fusion between autophagosomes and lysosomes, thereby blocking autophagosome degradation. As expected, $\mathrm{NH}_{4} \mathrm{Cl}$ pretreatment further increased accumulation of punctate GFP-LC3 in LPS-treated cells, suggesting that LPS caused accumulation of autophagosomes by increasing formation of autophagosomes, but not by inhibiting degradation of spontaneously forming autophagosomes. Quantification of GFP-LC3 punctated cells revealed that treatment with LPS increased the percentage of GFP-LC3 punctate cells from the basal level of $3 \%$ to $21 \%(P<0.05)$ (Figure $1 \mathrm{~B})$. Immunoblot analysis demonstrated that the conversion from LC3-I to LC3-II appeared at 12 hours of LPS treatment, reached a peak at 48 hours, and gradually declined at 72 hours (Figure 1 , C and D). The elevated Beclin-1 and Atg12-Atg5 conjugate protein levels were consistent with the increase of LC3-II, further indicating the activation of autophagy. Additionally, these effects were also LPS-dose dependent (Figure 1, $\mathrm{E}$ and $\mathrm{F}$ ). Notably, $\mathrm{NH}_{4} \mathrm{Cl}$ augmented the LPSmediated accumulation of LC3-II, which was above the levels induced by LPS exposure only (data not shown).

A sublethal dose of LPS could trigger apoptosis in various cell types. ${ }^{1,3,39,40}$ We further explored the effect of LPS on apoptosis in HMrSV5 cells by flow cytometry using an Annexin V-FITC Apoptosis Detection Kit. Apoptosis was only observed under higher concentrations of LPS (5 to $10 \mu \mathrm{g} / \mathrm{mL}$ ) exposure for 48 hours in HMrSV5 cells (Figure 2, A and B). Exposure of cells to LPS at 1 $\mu \mathrm{g} / \mathrm{mL}$ for 48 hours did not induce apoptosis, whereas apoptosis was observed when cells were incubated for 72 hours (Figure 2, C and D). Interestingly, incubation of $1 \mu \mathrm{g} / \mathrm{mL}$ LPS for 48 hours was sufficient to induce au- 
A
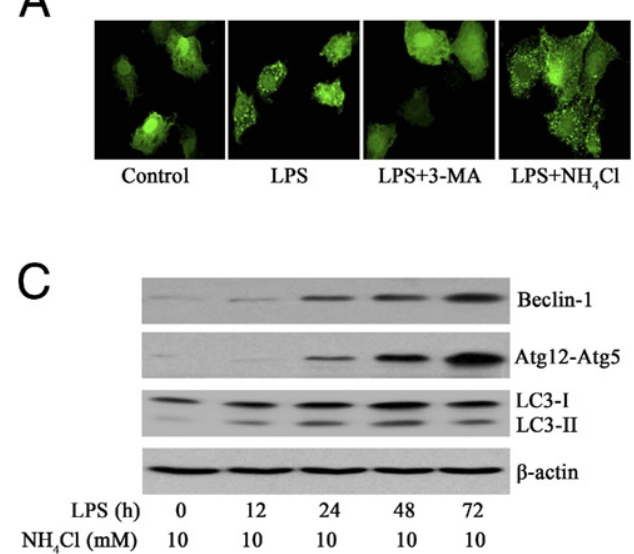

E

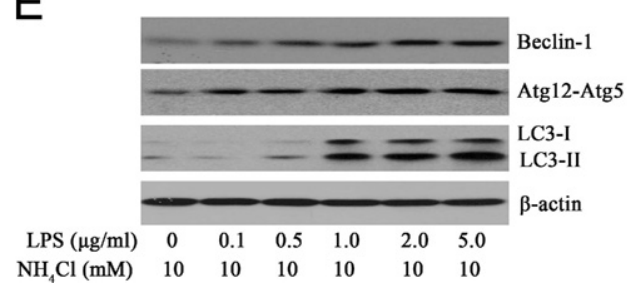

B
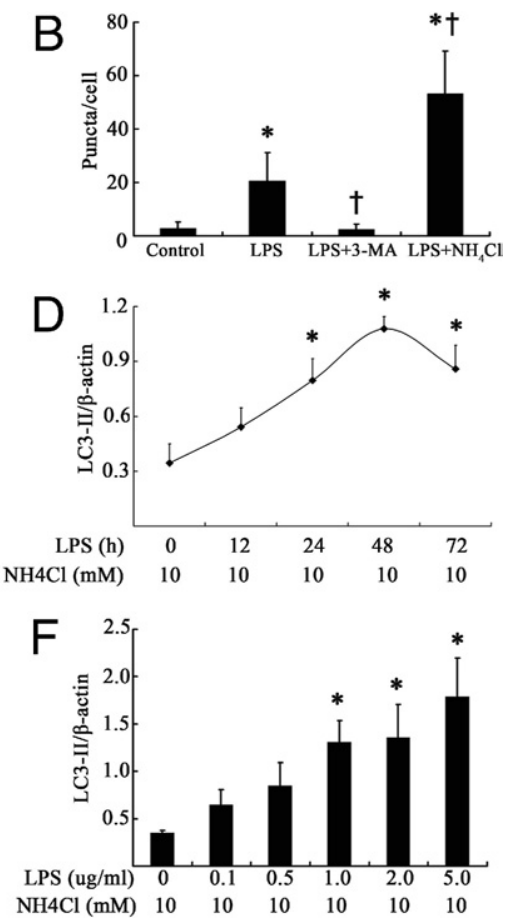

Figure 1. LPS induces autophagy in HMrSV cells. A: The cells transiently transfected with GFP-LC3 expression plasmid were treated with LPS $(1 \mu \mathrm{g} / \mathrm{mL})$ for 48 hours in the absence or presence of 3 -MA $(10 \mathrm{mmol} / \mathrm{L})$ or $\mathrm{NH}_{4} \mathrm{Cl}(10$ $\mathrm{mmol} / \mathrm{L}$ ). Formation of LC3 puncta was analyzed by immunofluorescence under confocal microscopy $(\times 400)$. B: Quantitative analysis of GFPLC3 puncta from each condition. Two hundred GFP-labeled cells randomly selected from 20 different fields were counted. Data were expressed as means $\pm \mathrm{SE}(n=3) .{ }^{*} P<0.05$ versus control group; ${ }^{\dagger} P<0.05$ versus LPS treated alone group. C: Cells were treated with $1 \mu \mathrm{g} / \mathrm{mL}$ of LPS in the present of $\mathrm{NH}_{4} \mathrm{Cl}$ for the indicated time period. Cell lysates were probed with antibodies against Beclin-1, Atg12-Atg5, and LC3. $\beta$-Actin was used as a loading control. D: Densitometry of LC3-II proteins in immunoblots. Data are means $\pm \mathrm{SE}$ $(n=3) .{ }^{*} P<0.05$ versus control group. E: Cell lysates from cells treated with LPS at various concentrations for 48 hours were analyzed by immunoblotting with the indicated antibodies. F: Quantitative determination of the relative abundance of the indicated proteins among different groups. Data are mean $\pm \mathrm{SE}(n=3) .{ }^{*} P<$ 0.05 versus control group. tophagy in this cell type (Figure 1, C and D). Similar results were obtained in primary HPMCs (Figure 3, A-D) and RPMCs (Figure 3, E-H) exposed to $1 \mu \mathrm{g} / \mathrm{mL}$ LPS. Collectively, these data suggest that the lower dose of LPS stimulation leads to autophagy before apoptosis in cultured peritoneal mesothelial cells.

\section{Inhibition of Autophagy Sensitizes Cells to LPS-Induced Apoptosis}

Autophagy plays a role in either promoting cell survival or cell death, depending on the cell type, the type of stress, and its duration. ${ }^{41,42}$ To address the role of autophagy in HMrSV5 cells, we first treated cells with 3-MA to inhibit autophagy. As expected, 3-MA attenuated the LPS-induced LC3-I to LC3-II conversion in a dose-dependent manner (Figure 4A). 3-MA pretreatment increased the apoptotic cells from $11.8 \%$ to $24.6 \%$ at 48 hours exposure to $1 \mu \mathrm{g} / \mathrm{mL}$ LPS (Figure $4 \mathrm{~B}$ ), indicating that inhibition of autophagy sensitizes HMrSV5 cells to the apoptosis. Next, we tested the effect of knockdown of the autophagic gene Beclin-1 on cell apoptosis. The transfection of Beclin-1 siRNA, but not scrambled siRNA, efficiently and specifically reduced Beclin-1 protein expression, which reached a maximum at $100 \mathrm{nmol} / \mathrm{L}$ (data not shown). Further, treatment with Beclin-1 siRNA at $100 \mathrm{nmol} / \mathrm{L}$ decreased punctate GFP-LC3 as shown by immunofluorescent microscopy (Figure 4C) and reduced the formation of LC3-II as indicated by immunoblot analysis (Figure 4D). Consistent with results obtained from the pharmacological inhibitor of autophagy, selective knockdown of Beclin-1 also enhanced cell apoptosis both at lower and higher doses of LPS (Figure 4E). Taken together, these findings suggest that the early autophagic response may exert protective effects against LPS-induced apoptosis in HMrSV5 cells.

\section{HSP72 Enhances Autophagy and Attenuates LPS-Mediated Apoptosis}

Recently, we and others have demonstrated an antiapoptotic effect of HSP72 in vitro and in vivo. ${ }^{31,43}$ To investigate the potential roles of HSP72 on autophagy in LPSstimulated HMrSV5 cells, we modulated HSP72 content using RNA interference and overexpression techniques. As shown in Figure 5A, HSP72 overexpression increased LPS-induced expression of Beclin-1 and LC3-II formation, but had no effect on the protein level of Atg12-Atg5 conjugate. Conversely, silencing of HSP72 inhibited these responses. Quantitative analysis showed that overexpression of HSP72 increased LC3-II protein by $65 \%$ at 60 multiplicities of infection of adenoviruses, compared with negative control (Figure 5B). Transfection with reagent alone (mock), scramble siRNA or infection with control adenovirus did not affect the expression of LC3-II and Beclin-1 (data not shown). In line with these results, overexpression of HSP72 augmented LPS-triggered formation of GFP-LC3 puncta as assessed by confocal immunofluorescent microscopy (Figure 5C). Notably, enhanced HSP72 content effectively protected cells from LPS-stimulated apoptosis at $5 \mu \mathrm{g} / \mathrm{mL}$ LPS for 48 hours (Figure 5D), whereas HSP72 siRNA essentially eliminated this effect (Figure 5D, column 4). Furthermore, suppression of autophagy with either 3-MA (Figure 5D) or Beclin-1 siRNA (Figure 5D) also inhibited the protective effects of HSP72 against apoptosis as shown by reduction of $\mathrm{Bcl}-2$ protein level, increasing of caspase 3 activation (Figure 5E), and acceleration of apoptosis 
A

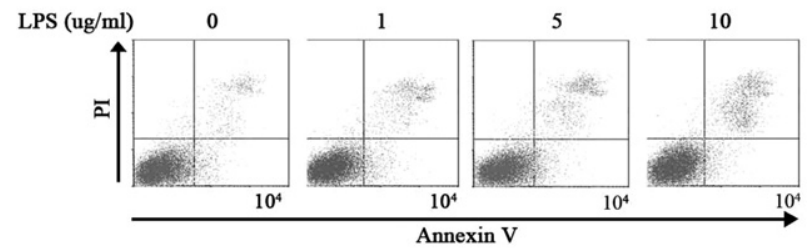

B

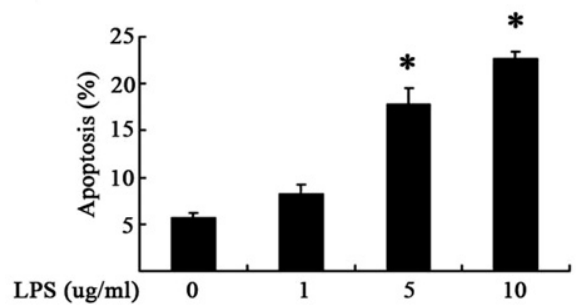

C

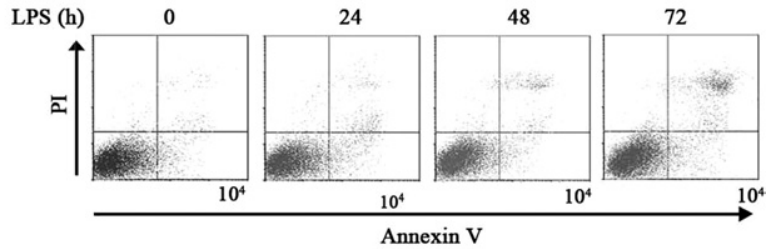

D

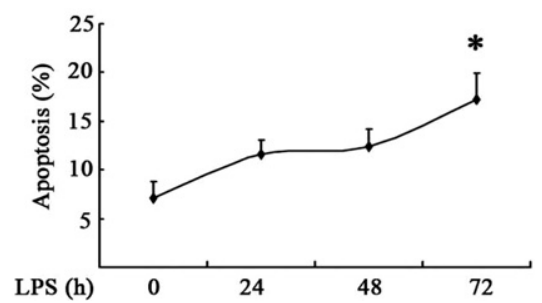

Figure 2. LPS induces apoptosis in HMrSV5 cells. A: To quantify cell apoptosis after treatment with LPS at the indicated concentrations for 48 hours, cells were trypsinized and collected, then stained with Annexin V/PI and subjected to FACS. B: The percentage of apoptosis among different groups. C: Cells were treated with $1 \mu \mathrm{g} / \mathrm{mL}$ LPS and apoptosis was examined by FACS at the indicated time. D: The percentage of apoptosis. Data in $(\mathbf{B}$ and $\mathbf{D})$ are expressed as means $\pm \mathrm{SE}(n=5) .{ }^{*} P<0.05$ versus control group.

(Figure 5D). Collectively, these results indicate that autophagy contributes to HSP72-mediated cytoprotection in LPS-induced apoptosis of peritoneal mesothelial cells.

\section{HSP72 Increases Autophagy Through Phosphorylation of JNK}

JNK-mediated Beclin-1 expression plays a pivotal role in autophagosome formation. ${ }^{44}$ To determine the molecular mechanism(s) by which HSP72 augments autophagy, we evaluated the impact of HSP72 on JNK activation. We found that overexpression of HSP72 increased LPSinduced phosphorylation of JNK1 and JNK2 and the expression of Beclin-1, whereas these effects were reversed in cells treated with HSP72 siRNA (Figure 6, A and $B$ ).

To examine whether JNK activation is required for HSP72 regulating autophagy, HMrSV5 cells were treated with LPS in the presence or absence of SP600125, a specific JNK inhibitor. Compared with LPS-treated cells alone, SP600125 pretreatment prevented LPS-stimulated the increase in Beclin-1 and LC3-II expression, which is consistent with other reports. ${ }^{44-46}$ Moreover, SP600125 blocked HSP72-mediated up-regulation of Beclin-1 and LC3-II in response to LPS stimulation (Figure 6, C and D). Similar results were also obtained in cells treated with siRNA directed against JNK1/2 (Figure 6, E and F). These data indicate that JNK phosphorylation is necessary for HSP72-enhanced autophagy.

\section{LPS Induces Peritoneal Mesothelial Cell Autophagy before Apoptosis in Rats}

To assess the interplay between autophagy and apoptosis in vivo, we generated acute peritonitis in rats by intraperitoneal injection of LPS as previously described. ${ }^{32,33}$ As shown in Figure 7, A and B, accumulation of LC3-II was evident in peritoneum following LPS injection, which was maximal at 24 hours and decreased at 48 hours. LPS also triggered a time-dependent expression of both Beclin-1 and Atg12-Atg5 conjugate, analogous to our in vitro observations. Immunofluorescence analysis showed a
A
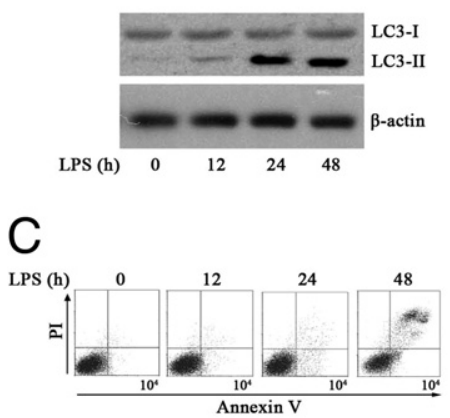

E

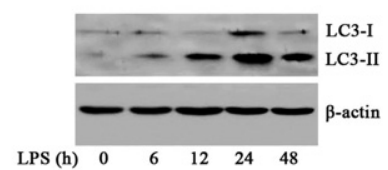

G

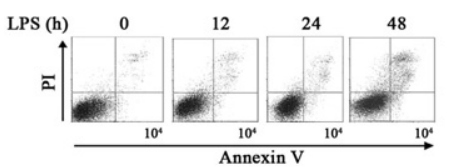

B
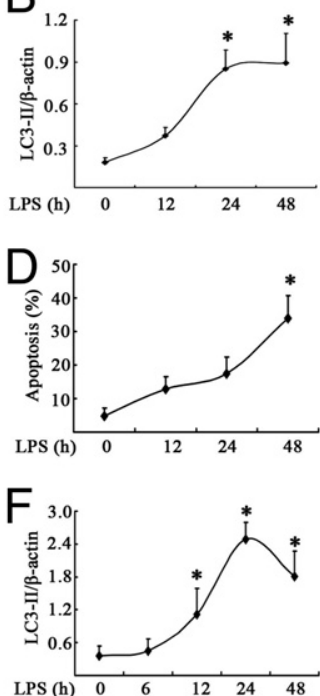

$\mathrm{H}$

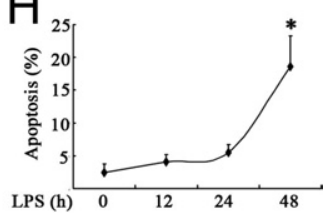

Figure 3. LPS triggers autophagy/apoptosis in HPMCs and RPMCs. Both HPMCs and RPMCs were treated with $1 \mu \mathrm{g} / \mathrm{mL}$ of LPS for the indicated time. A: HPMCs cell lysates were probed with antibodies against LC3. $\beta$-Actin was used as loading control. B: Densitometry of LC3-II proteins in immunoblots. Data are means $\pm \mathrm{SE}(n=3) .{ }^{*} P<0.05$ versus control group. $\mathbf{C}$ : The time course of LPS-induced apoptosis in HPMCs. Apoptosis was assessed by FACS. D: The apoptotic rate in HPMCs among different groups. E: Immunoblot analysis of LC3 in RPMCs treated with LPS. F: Densitometric analysis of LC3-II from at least four separate experiments. G: The effect of LPS-induced apoptosis in RPMC cells was examined by FACS. H: The apoptotic rate in LPS-stimulated RPMC cells. Data in $\mathbf{B}, \mathbf{D}, \mathbf{F}$, and $\mathbf{H}$ are expressed as means \pm SE $(n=5) .{ }^{*} P<0.05$ versus control group. 
A

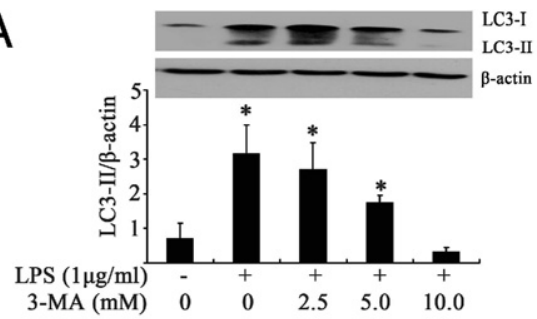

C
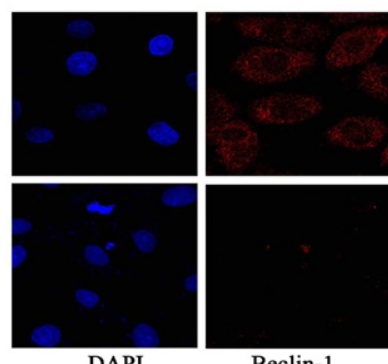

DAPI

D

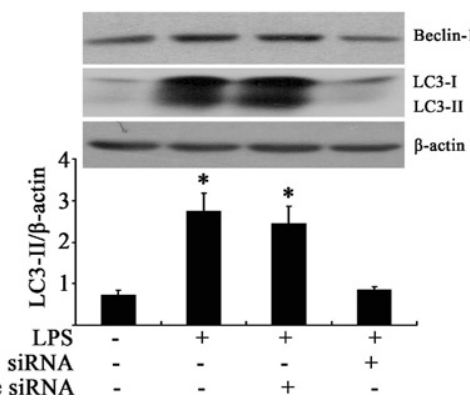

B
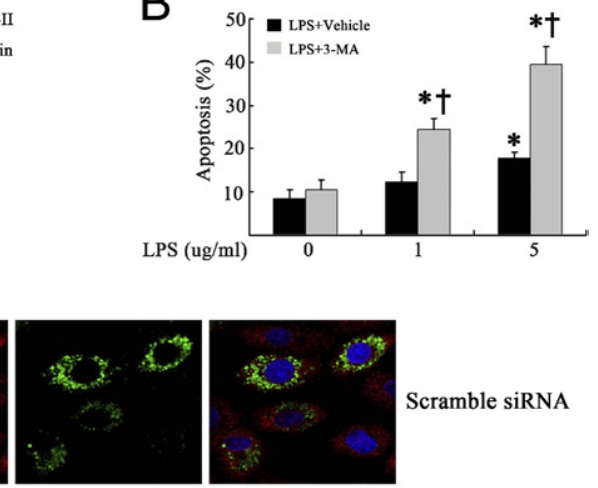

Scramble siRNA

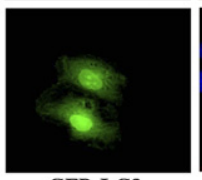

GFP-LC3

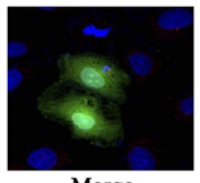

Merge

E

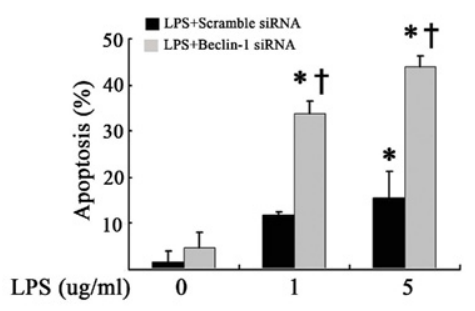

Figure 4. Inhibition of autophagy by 3-MA or knockdown of Beclin-1 expression sensitize cells to LPS-induced apoptosis. A: Cells were pretreated with the indicated concentrations of 3-MA for 1 hour before exposure to LPS ( $1 \mu \mathrm{g}$ / $\mathrm{mL})$ for an additional 48 hours. Immunoblot and densitometric analysis of LC3 in cells treated with LPS or LPS + 3-MA. B: Cells were incubated with $1 \mu \mathrm{g} / \mathrm{mL}$ or $5 \mu \mathrm{g} / \mathrm{mL}$ LPS for 48 hours in the absence or presence of 3-MA. Effects of 3-MA on LPS-induced apoptosis were determined by FACS. Data are expressed as means $\pm \mathrm{SE}(n=$ 5). ${ }^{*} P<0.05$ versus control group; ${ }^{\dagger} P<0.05$ versus LPS-treated cells without 3-MA. C: Cells were transfected with Beclin-1 siRNA (100 $\mathrm{nmol} / \mathrm{L}$ ) or scrambled siRNA and exposed to 1 $\mu \mathrm{g} / \mathrm{mL}$ LPS for 48 hours. Representative confocal microscopic images showed the GFP-LC3 puncta (green) and Beclin-1 (red) by indirect immunofluorescence staining in cells (original magnification, $\times 400)$. D: Cells were treated as described in C. Beclin-1 and LC3 protein contents were evaluated by Western blotting and densitometric analysis of LC3-II in immunoblots. E: Effects of knockdown of Beclin-1 expression on LPS-induced apoptosis were determined by FACS. Data are expressed as mean $\pm \operatorname{SE}(n=5)$. ${ }^{*} P<0.05$ versus LPS-untreated cells; ${ }^{\dagger} P<0.05$ versus LPS-treated cells with scramble siRNA. diffuse distribution of LC3 in the absence of LPS, whereas LPS administration exhibited a punctuate pattern of LC-3 fluorescence in peritoneal mesothelial cells (Figure 7C). The autophagosome formation was further confirmed by transmission electron microscope. As shown by representative micrographs, the cytoplasmic material or damaged organelles within the lumen of double- or multiplemembraned vesicles, the features of autophagosome
A

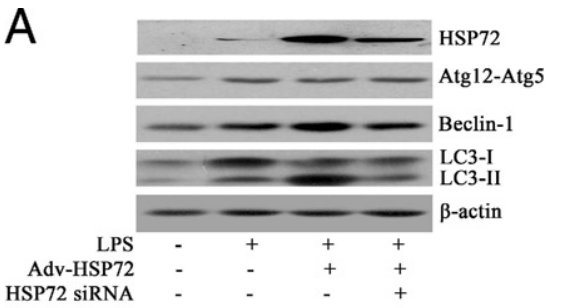

C
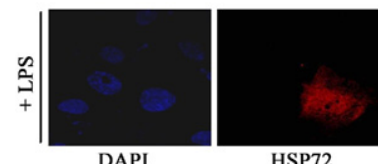

HSP72

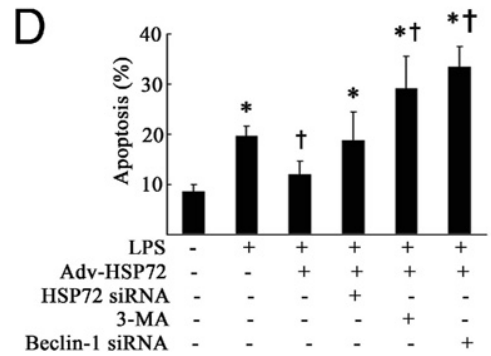

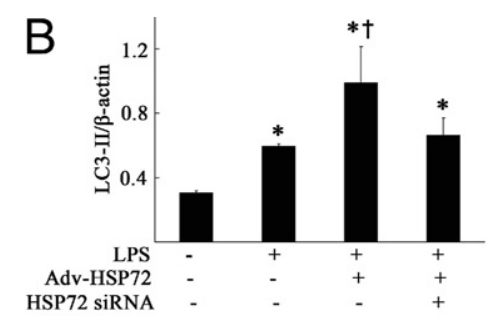

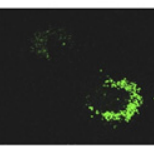

GFP-LC3

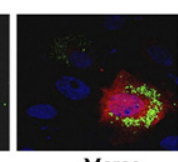

Merge

E

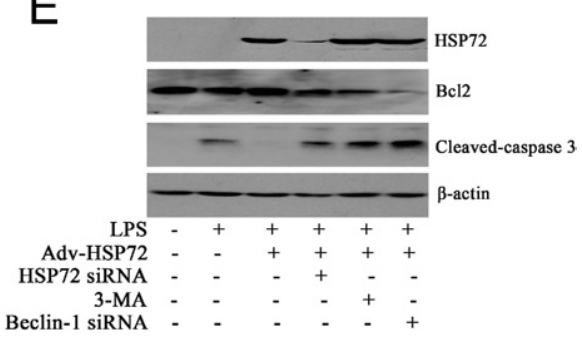

Figure 5. Inhibition of autophagy blocks HSP72 cytoprotection in HMrSV5 cells. A: Cells were up-regulated or down-regulated HSP72 for24 hours following LPS $(5 \mu \mathrm{g} / \mathrm{mL})$ exposure for another 48 hours. Empty vector served as negative control. LC3, Beclin-1, and Atg12-Atg5 protein contents were determined by Western blotting. B: Expression levels of the indicated proteins were evaluated by densitometric analysis and normalized with $\beta$-actin. C: Representative images of GFP-LC3 (green) staining in LPStreated cells with HSP72 (red) overexpression. D: Cells were pretreated with Beclin-1 siRNA $(100 \mathrm{nmol} / \mathrm{L})$ for 24 hours or 3 -MA $(10 \mathrm{mmol} / \mathrm{L})$ for 1 hour to suppress autophagy and then with overexpressed or down-regulated HSP72 for 24 hours following LPS $(5 \mu \mathrm{g} / \mathrm{mL})$ exposure for another 48 hours. Empty vector served as negative control. Apoptosis was assessed by FACS among different groups. The number of apoptotic cells was expressed as the percentage of total cells. E: The protein levels of HSP72, Bcl-2, and caspase 3 cleavage fragments were examined by immunoblotting assay. Data in $\mathbf{B}$ and $\mathbf{D}$ were means $\pm \operatorname{SE}(n=3) .{ }^{*} P<0.05$ versus negative control; ${ }^{\dagger} P<0.05$ versus ${ }^{\top} P S$-alone treated cells. 
A

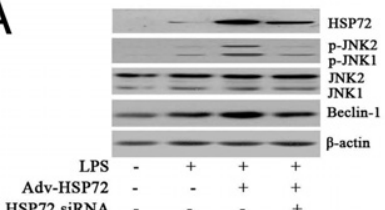

C

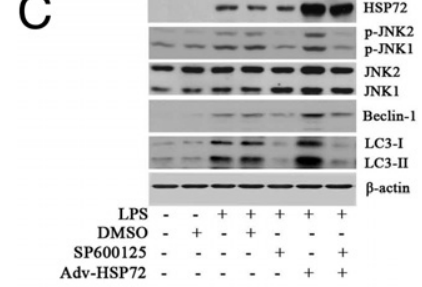

$\mathrm{E}$

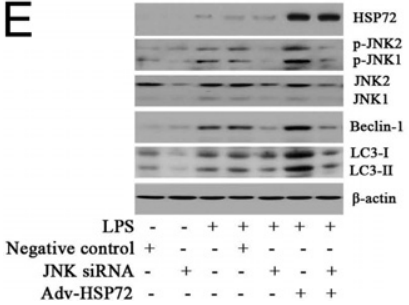

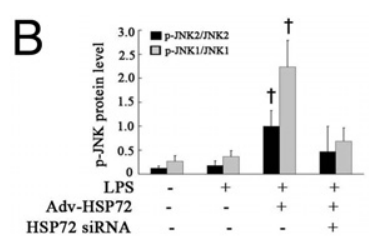
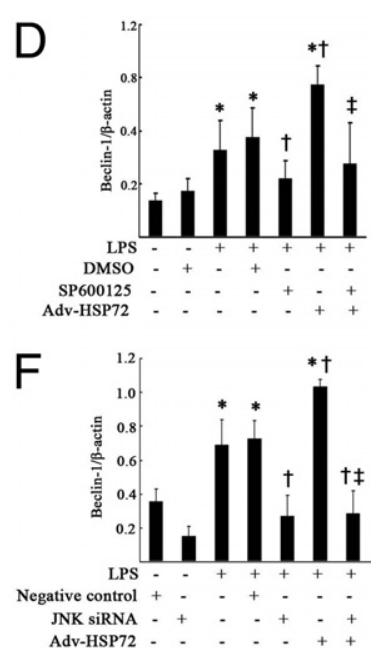

Figure 6. Activation of JNK is required for HSP72-mediated autophagy enhancement. A: Cells were treated with Adv-HSP72 or HSP72 siRNA followed by stimulation with LPS $(1 \mu \mathrm{g} / \mathrm{mL})$ for 48 hours. Empty vector served as negative control. HSP72, Beclin-1, JNKs, and p-JNKs were examined by Western blotting. B: p-JNK1 and p-JNK2 contents were quantitatively analyzed using a densitometer. Values are means \pm SE $(n=3) .{ }^{\dagger} P<0.05$ versus LPS-treated cells with or without HSP72 siRNA. C: Cells were pretreated with a JNK-specific inhibitor, SP600125 (10 $\mu \mathrm{mol} / \mathrm{L})$, to suppress JNK phosphorylation and then infected with Adv-HSP72 following LPS exposure for 48 hours. Cell lysates were probed with antibodies against HSP72, Beclin-1, JNKs, p-JNKs, or $\beta$-actin. D: Expression levels of Beclin-1 were evaluated by densitometric analysis and normalized with $\beta$-actin. E: Cells were pretreated with JNK siRNA $(100 \mathrm{nmol} / \mathrm{L})$ and then infected with Adv-HSP72 following LPS exposure for 48 hours. Cell lysates were probed with the indicated antibodies. F: Densitometry of Beclin-1 in immunoblots. Data in D and F are mean $\pm \mathrm{SE}(n=3) .{ }^{*} P<0.05$ versus control group; ${ }^{\dagger} P<0.05$ versus LPS-treated cells alone; ${ }^{\ddagger} P<0.05$ versus LPS-treated cells with HSP72 overexpression and without SP600125 or JNK siRNA.

were present in the peritoneal mesothelial cells after LPS administration (Figure 7, D and E).

We also analyzed apoptosis in the peritoneum by TUNEL assay. As shown in Figure 7, $\mathrm{F}$ and $\mathrm{G}$, apoptosis was not observed in the peritoneum until after 48 hours of LPS administration. These results demonstrate that both autophagy and apoptosis occur in peritoneal mesothelial cells in rats, but that LPS-mediated autophagy occurs before apoptosis.

\section{Selective Up-Regulation of HSP72 by GGA Improves LPS-Induced Peritonitis}

Our previous studies and others have demonstrated that GGA selectively induces HSP72, and quercetin is known to strongly inhibit the HSP72 synthesis. ${ }^{25,31,34,47}$ To evaluate the effects of HSP72 on LPS-induced cell autophagy and apoptosis in vivo, GGA and quercetin were used to regulate HSP72 expression in rats. In line with our previous observation, oral administration of GGA markedly increased the expression of HSP72, but not HSP90 and HSP27, of the peritoneum in the presence or absence of
LPS treatment. whereas, quercetin pretreatment effectively suppressed the GGA-induced HSP72 increase (Figure 8, A and B).

Acute peritonitis developed in 48 hours, following a single intraperitoneal injection of LPS. As shown in Figure $8 \mathrm{C}$, the white blood cell counts in the effluent of rats with LPS injection were higher than that in the control group. GGA pretreatment markedly ameliorated the LPS-induced increase in white blood cells in the effluent. This event was blocked by quercetin. In addition, by morphological analysis, normal rat mesothelial cells formed a thin uniform monolayer. In contrast, a reduction of the integrity and the number of linear mesothelial cells and a discernable submesothelial edema were evident in LPS-induced peritonitis. All these pathological changes were attenu-
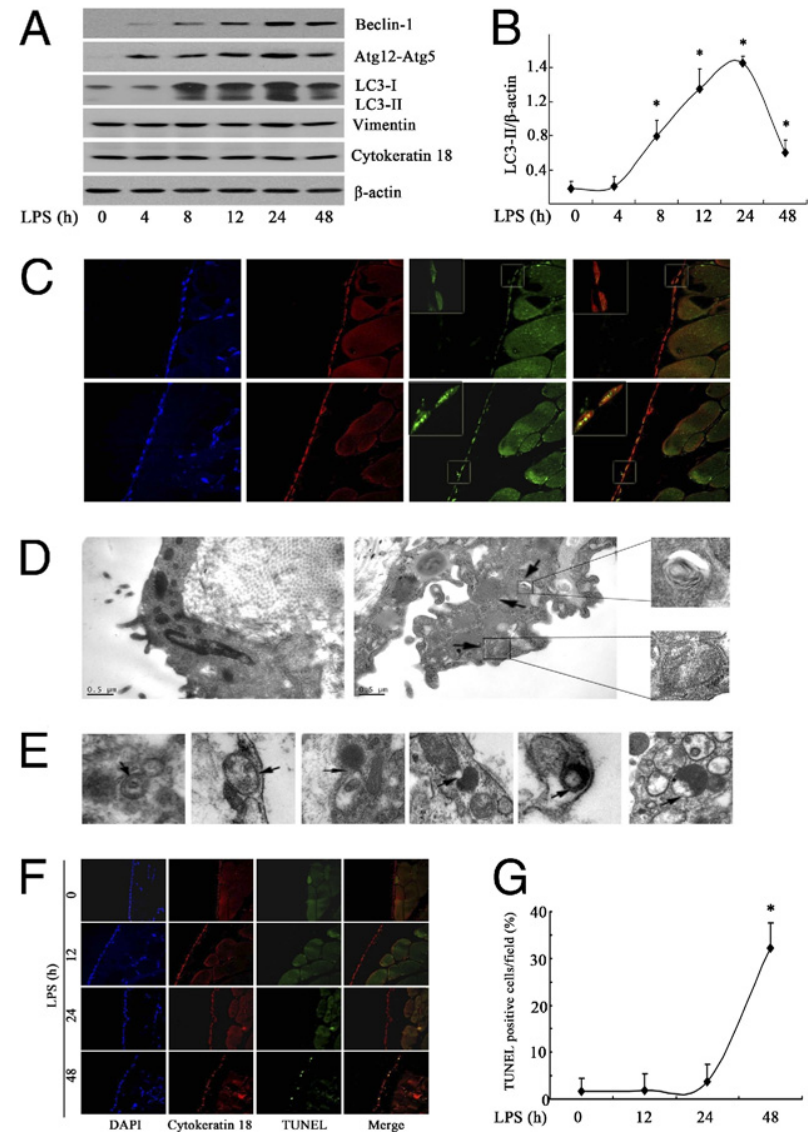

Figure 7. LPS induces autophagy and apoptosis in peritoneal tissue in vivo Male Sprague-Dawley rats were injected intraperitoneally with $1 \mathrm{mg} / \mathrm{kg}$ LPS At the indicated time points, the peritoneal tissues were collected for studies. A: Representative immunoblots of LC3 in visceral peritoneal homogenates. Vimentin and cytokeratin 18 were used as additional loading controls for the peritoneal mesothelial cells fraction. B: Densitometric analysis of the effect of LPS on autophagy and autophagy promoting proteins. Data are mean $\pm \mathrm{SE}$ $(n=5) .{ }^{*} P<0.05$ versus vehicle control. C: Representative immunofluorescence analysis of LC3 in parietal peritoneum (original magnification, $\times 400$ ) Inserts showed particular areas at higher magnification to better visualize the LC3 punctate. D: Representative electron micrographs showing autophagosomes in LPS-treated cells (arrows indicate autophagosomes) (scale bar = $0.5 \mu \mathrm{m}$ ). E: Selected high magnification of electron micrographs showing the assembly and progression of autophagic vesicles (arrows indicate autophagosomes or autophagolysosomes) (scale bar $=200 \mathrm{~nm}$ ). F: Representative images of TUNEL staining (green) and cytokeratin 18 (red) in parietal peritoneal tissue (original magnification, $\times 400$ ). G: Quantitative analysis of TUNEL-positive cells in the indicated times. Data in $\mathbf{B}$ and $\mathbf{G}$ are means $\pm \mathrm{SE}$ $(n=5) .{ }^{*} P<0.05$ versus vehicle control. 
A

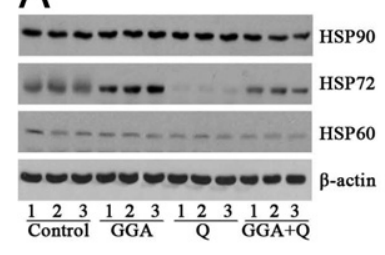

B

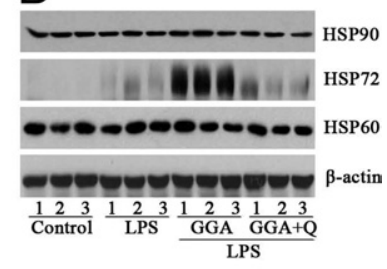

C

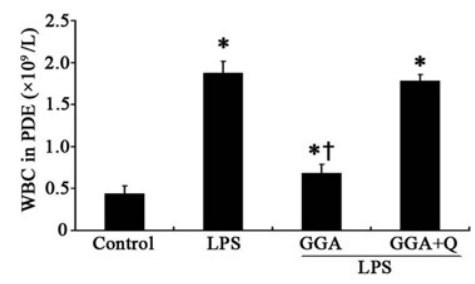

D
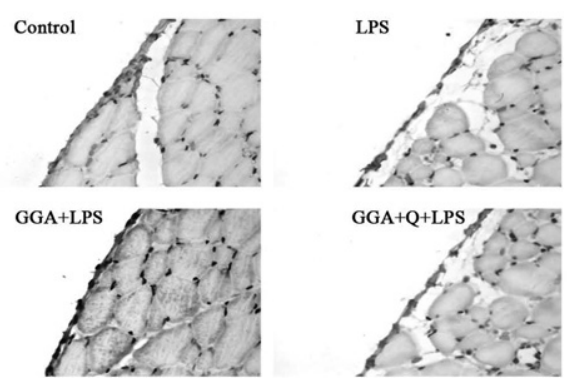

Figure 8. GGA attenuates LPS-associated peritonitis. A: The effects of GGA and quercetin on the expression of HSP90, HSP72, and HSP27 in peritoneum without LPS intraperitoneal injection. B: The effects of GGA and quercetin on the expression of HSP90, HSP72, and HSP27 in peritoneum after LPS intraperitoneal injection. C: White blood cell (WBC) counts in peritoneal dialysis effluent (PDE). D: Representative parietal peritoneum histology among different groups. Tissue sections are stained with HSP72. Original magnification, $\times 400$.

ated by GGA treatment, which was associated with an increase of HSP72 expression in peritoneum. Moreover, quercetin administration blocked the up-regulation of HSP72 and reversed the protective effect of GGA (Figure 8D). Taken together, these results suggest that suppression of LPS-induced peritonitis by GGA might be related to up-regulation of HSP72.

\section{Enhancement of Autophagy by HSP72 Attenuates LPS-Induced Peritoneal Injury}

We then examined the role of HSP72 in autophagy. As shown in Figure 9, A and B, GGA resulted in increased JNK1 and JNK2 phosphorylation, and elevated Beclin-1 expression and LC3-II accumulation, whereas quercetin abolished these effects of GGA. However, neither GGA nor quercetin altered the expression of Atg12-Atg5 conjugate during acute peritonitis. Ultrastructural analyses by transmission electron microscopy confirmed that LPS significantly induced autophagosome formation. GGA administration further accelerated LPS-induced formation of autophagosomes. In contrast, down-regulation of HSP72 by quercetin essentially blocked these effects of GGA (Figure 9C), supporting increased autophagy activity by HSP72 overexpression. Consistent with the timeline of autophagy in peritoneum, GGA treatment reduced apoptotic cells (Figure 9D). In addition, rats with acute
LPS-associated peritonitis were accompanied by increased small solute transport (urea and glucose) and loss of ultrafiltration. All these alterations were significantly attenuated in GGA pretreated rats, suggesting improvement of the peritoneal function. However, these protective impacts of GGA were suppressed by quercetin pretreatment (Figure 9, E-G). Of note, both GGA and quercetin per se did not cause obvious cell toxicity in rats (data not shown).

\section{Suppression of Autophagy by Chloroquine Exacerbates LPS-Associated Peritoneal Injury}

It has been demonstrated that induction of HSP72 is involved in protecting the organism from inflammation by regulating expression of inflammation genes. To determine whether autophagy enhancement rather than an anti-inflammation property contributes to the protective effect of HSP72 in LPS-related peritoneal damage, we used $C Q$, an autophagy-specific inhibitor that suppresses autophagosome-lysosome fusion and lysosomal protein degradation, to block the last step of the autophagic process. Compared with the LPS-alone group, CQ pretreatment further enhanced LPS-induced accumulation of LC3-II, as demonstrated by immunoblot analysis (Figure 10, A and B), and thus increased TUNELpositive cells in the peritoneum (Figure 10, C and D). Consistently, LPS-induced dysfunction of peritoneal transport was more evident in CQ pretreated rats compared with that in LPS-alone treated animals (Figure 10, $E-G)$. These results further confirm that autophagy functions to prevent peritoneal damage and suggest that HSP72 preserves peritoneal function in LPS-associated peritonitis, at least partly, by enhancing autophagy.

\section{Discussion}

In this study, we demonstrate that LPS induces autophagy before apoptosis in peritoneal mesothelial cells both in vitro and in vivo. Blockade of autophagy through pharmacological or genetic approach sensitizes cells to apoptosis. Overexpression of HSP72 protects against LPS-mediated apoptosis, partially through autophagy induction. Moreover, overexpression of HSP72 increases JNK phosphorylation and Beclin-1 expression. Suppression of JNK activation abrogates the HSP72-mediated up-regulation of Beclin-1 and enhancement of autophagy, suggesting that JNK activation is required for HSP72's cytoprotective mechanism. Importantly, increased HSP72 by GGA augments autophagy, inhibits apoptosis, and improves peritoneal function in LPS-associated rat peritonitis. These results suggest that autophagy is a prosurvival mechanism for peritoneal mesothelial cells in LPS-induced injury. Furthermore, as summarized in Figure 11, HSP72 rescues peritoneal mesothelial cells from apoptosis and preserves peritoneal function, at least in part, through mechanisms involved in the JNK-mediated up-regulation of Beclin-1 and autophagy, concurrently increasing $\mathrm{Bcl}-2$ protein level and reducing caspase 3 activation. 
A

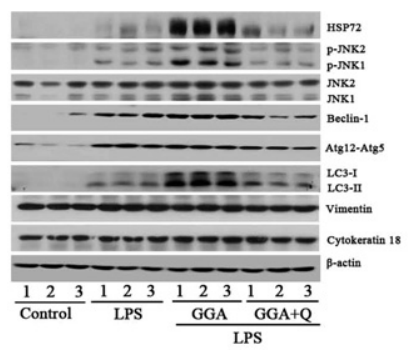

B

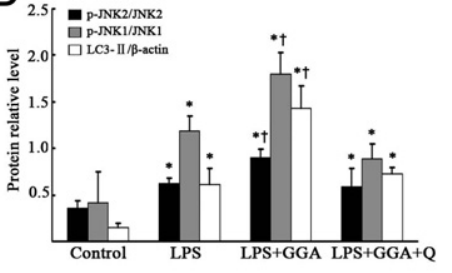

D

C
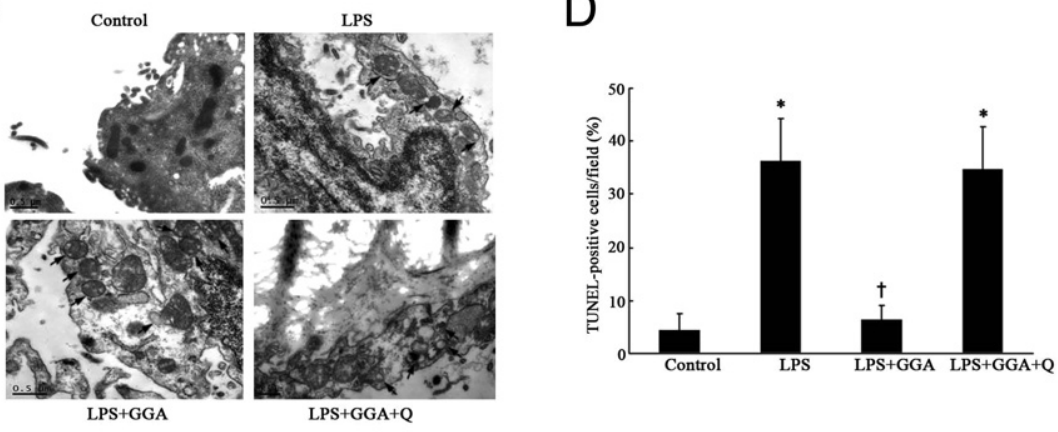

$\mathrm{E}$

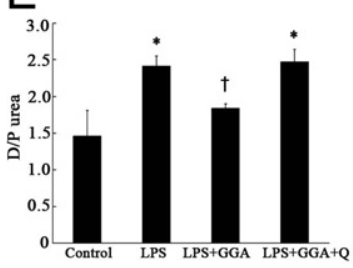

$\mathrm{F}$

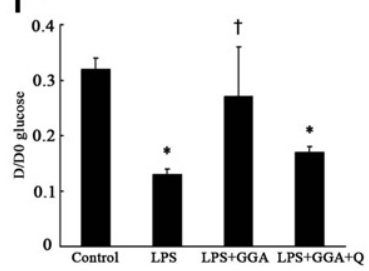

G

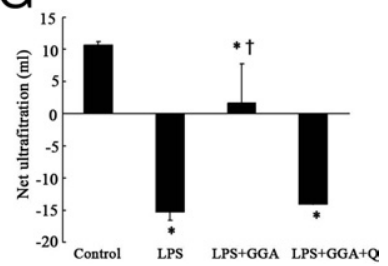

Figure 9. HSP72 enhances LPS-induced autophagy and protects peritoneal membrane against injury in rats. A: Expression levels of HSP72 in peritoneum were up-regulated and down-regulated by GGA and quercetin (Q) administration, respectively, as described in Materials and Methods. At the 48th hour after LPS intraperitoneal injection, the peritoneum was collected for analysis of the indicated proteins. B: Protein expression levels of the indicated proteins were quantified by densitometry and normalized with $\beta$-actin. C: Representative electron micrographs showed autophagosomes or autolysosomes in each condition (arrows indicate autophagosomes or autophagolysosomes) (scale bar $=0.5 \mu \mathrm{m}$ ). D: Cell apoptosis in the peritoneum was evaluated by TUNEL assay. Quantitative analysis of TUNEL-positive cells in each condition. E-G: Peritoneal permeability to glucose and urea and ultrafiltration among different groups. Values are expressed as D/P urea, $\mathrm{D} / \mathrm{D}_{0}$ glucose, or net ultrafiltration. Data in $\mathbf{B}, \mathbf{D}$ $\mathbf{E}, \mathbf{F}$, and $\mathbf{G}$ are mean $\pm \operatorname{SE}(n=5) .{ }^{*} P<0.05$ versus vehicle control; ${ }^{\dagger} P<0.05$ versus LPStreated without GGA or quercetin administration.
Autophagy is thought to be involved in various physiological and pathological events. It is well documented that LPS induces autophagy in numerous cell types. ${ }^{6-8,48}$ However, it has never been investigated whether autophagy occurs and if so, what pathophysiological role it plays in the peritoneal mesothelial cells and tissues. In the in vitro study, we showed that autophagy occurred in HMrSV5 cells at 24 hours of $1 \mu \mathrm{g} / \mathrm{mL}$ LPS exposure, as demonstrated by punctate GFP-LC3 localization and LC3-II formation. These alterations were associated with the corresponding increased expression of Beclin-1 and Atg12Atg5 conjugate. However, apoptosis was not induced by the same concentration of LPS until 72 hours. Similar results were obtained in primary cultured human and rat peritoneal mesothelial cells. Of note, LPS treatment in the presence of the lysosomal inhibitor $\mathrm{NH}_{4} \mathrm{Cl}$ led to a further increase in accumulation of punctate GFP-LC3 or formation of LC3-II, suggesting that LPS induces autophagy by increasing the formation of autophagosomes rather than by decreasing the rate of degradation of these transient vesicles. Consistently, autophagy was also induced before peritoneal mesothelial cell apoptosis in LPS-associated peritonitis in rats.

Whether autophagy promotes or inhibits cell death is circumstantial. Some studies showed that inappropriate stimulation of autophagy may facilitate cell death, ${ }^{49,50}$ whereas other studies demonstrated that autophagy can serve as a prosurvival mechanism via inhibiting apoptosis. ${ }^{51,52}$ Given the fact that LPS induced both autophagy and apoptosis in peritoneal mesothelial cells, we examined the relationship between those two events. The results showed that inhibition of autophagy by either 3-MA or Beclin-1 siRNA increased LPS-induced HMrSV5 cells apoptosis. The effects were found, not only at higher concentrations, but also at lower concentrations of LPS treatment. In an in vivo rat model of LPS-related peritonitis, suppression of autophagy by $C Q$, not only sensitized peritoneal mesothelial cells to apoptosis, but also exacerbated peritoneal dysfunction as shown by decreased net ultrafiltration and increased peritoneal permeability of small solutes. Thus, these findings support the notion that the early induction of autophagy prevents peritoneal mesothelial cells from apoptosis and preserves the peritoneal function in LPS-associated peritonitis.

Ample evidence demonstrated that HSP72 can function as a molecular chaperone. ${ }^{53}$ Apart from being involved in the prevention of apoptosis from a variety of insults, ${ }^{24,54,55}$ HSP72 also contributes to chaperone-mediated autophagy. ${ }^{56,57}$ However, the role of HSP72 in macroautophagy induction in peritoneal mesothelial cells has not been investigated. Our data revealed that overexpression of HSP72 enhanced LPS-induced autophagy of peritoneal mesothelial cells, and concurrently reduced apoptotic death both in vitro and in vivo. Blockade of autophagy by 3-MA or Beclin-1 siRNA abolished the antiapoptotic effects of HSP72 in LPS-induced HMrSV5 cells. Importantly, induction of HSP72 by GGA promoted autophagy, inhibited apoptosis, and improved peritoneal 
A
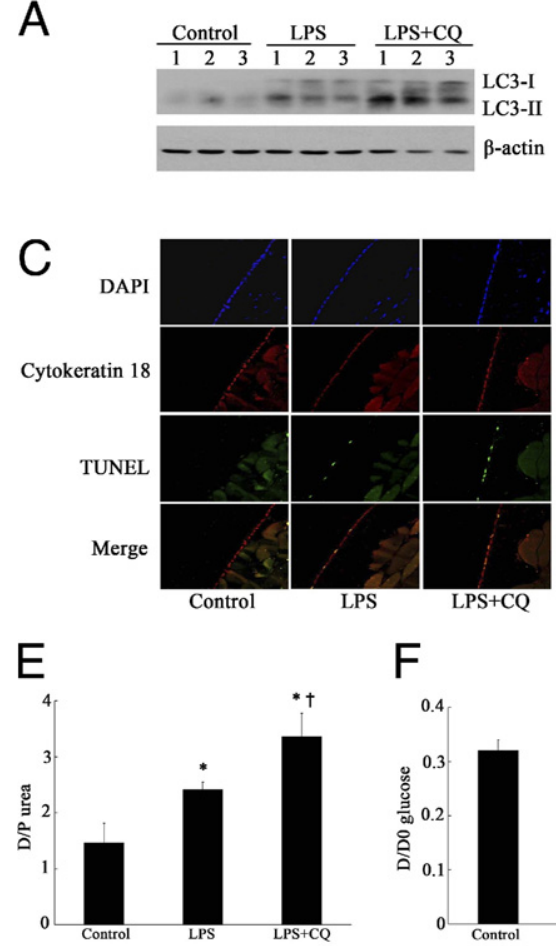

$\mathrm{F}$

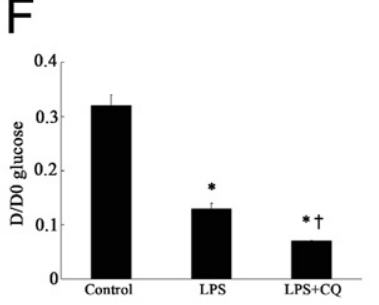

G

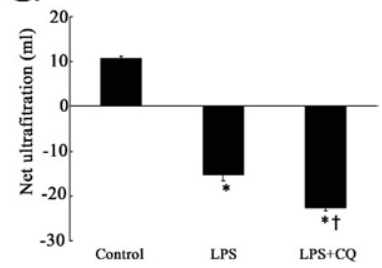

Figure 10. Chloroquine promotes LPS-associated peritoneal membrane injury in rats. A: Representative Western blot analysis showed the protein levels of LC3 and $\beta$-actin from rats peritoneum treated with vehicle, LPS, or LPS plus CQ. B: Densitometric analysis of LC3-II in immunoblots $(n=5)$. C: Representative pictures of TUNEL staining in parietal peritoneal tissues in different groups as indicated (× 400). D: Quantitative analysis of TUNEL positive cells among different groups. E-G: Peritoneal permeability to glucose and urea and ultrafiltration among different groups. Values are expressed as D/Purea, $\mathrm{D} / \mathrm{D}_{0}$ glucose, or net ultrafiltration. Data in $\mathbf{B}, \mathbf{D}$ $\mathbf{E}, \mathbf{F}$, and $\mathbf{G}$ were means $\pm \mathrm{SE}(n=5) .{ }^{*} P<0.05$ versus vehicle control; ${ }^{\dagger} P<0.05$ versus LPStreated without CQ administration. function in LPS-related peritonitis, and these protective effects of GGA on peritoneum were eliminated by downregulation of HSP72 with quercetin pretreatment. Previous studies have demonstrated an important role of HSP72 in preventing inflammation in the LPS-induced systemic inflammation model, ${ }^{58,59}$ raising the possibility that HSP72 may attenuate LPS-mediated peritoneal injury through reducing inflammation. In addition, in vivo animal studies with GGA and quercetin treatment could be complicated by their other pharmacological effects rather than sole HSP72 induction and inhibition. However, the

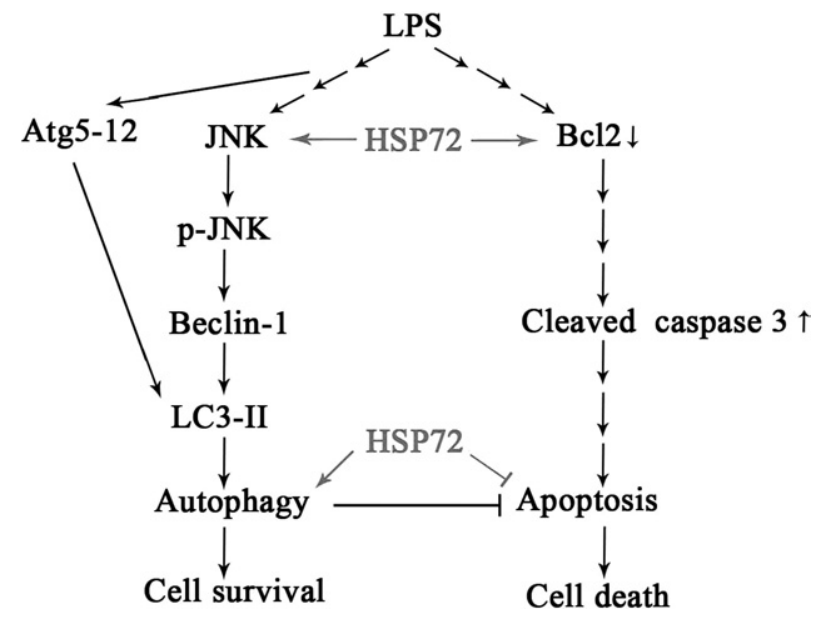

Figure 11. Schematic illustration of potential cell signaling involved in the survival mechanism by HSP72 in preventing LPS-induced apoptosis in peritoneal mesothelial cells. Overexpression of HSP72 protects peritoneal mesothelial cells against LPS-induced apoptosis by activating JNK to up-regulate Beclin-1 expression, thereby enhancing autophagy, perhaps concurrently, by increasing the $\mathrm{Bcl}-2$ protein level and reducing caspase 3 activation. results from the in vitro study using peritoneal mesothelial cells clearly showed that up-regulation of HSP72 with infection adenoviruses containing HSP72 cDNA promoted autophagy and inhibited apoptosis induced by LPS, and down-regulation of HSP72 with siRNA reduced or abolished the inhibitive effects of HSP72 on apoptosis, which supports the specific cytoprotective roles of HSP72 in our rat peritonitis model. Furthermore, our in vivo data, combined with the fact that the specific autophagy inhibitor (CQ) exacerbated LPS-associated peritoneal dysfunction, also provide strong evidence that HSP72 preserves peritoneal function in LPS-associated peritonitis, at least partly, by autophagy enhancement and apoptosis inhibition.

There are multiple mechanisms regulating autophagy. The functional role of JNK in cell survival and death is complex. A large number of reports state that JNK activation is an important mechanism for promoting apoptosis. However, there is also evidence suggesting that JNK activation is necessary for cell survival, although the underlying molecular mechanism is incompletely understood. JNK activation has been implicated in various models of autophagy, such as in response to serum starvation, cytokines, growth factor withdrawal, and neurotoxic drugs. ${ }^{60-63}$ Whether HSP72 regulates autophagy via JNK is unclear. Our studies showed that enhanced HSP72 expression activated JNK and increased Beclin-1 protein level, one of the essential components in autophagosome formation, which usually increases during autophagy through JNK activation, ${ }^{44,64}$ but did not affect the Atg12-Atg5 conjugate protein content. In addition, a specific inhibition of JNK by a JNK inhibitor or JNK siRNA abrogated HSP72-mediated increase in autophagy and 
up-regulation of Beclin-1 protein expression. Taken together, we concluded that JNK plays an important role in induction of autophagy, and HSP72 regulates LPS-induced autophagy through a JNK-dependent mechanism by up-regulation of Beclin-1 in peritoneal mesothelial cells.

In conclusion, our study reveals that activation of autophagy is a prosurvival mechanism in LPS-associated peritoneal injury. HSP72 protects peritoneum integrity and function in LPS-induced peritonitis, at least in part, via JNK activation-dependent autophagy. Thus, we propose that enhancing autophagy through up-regulation of HSP72 expression may be a potential therapeutic strategy in PD-related peritonitis.

\section{Acknowledgments}

We thank Prof. Zheng Dong (Medical College of Georgia) for critical discussion.

\section{References}

1. Vernooy JH, Dentener MA, van Suylen RJ, Buurman WA, Wouters EF: Intratracheal instillation of lipopolysaccharide in mice induces apoptosis in bronchial epithelial cells: no role for tumor necrosis factoralpha and infiltrating neutrophils. Am J Respir Cell Mol Biol 2001, 24:569-576

2. Bohlinger I, Leist M, Gantner F, Angermuller S, Tiegs $G$, Wendel $A$ : DNA fragmentation in mouse organs during endotoxic shock. Am $J$ Pathol 1996, 149:1381-1393

3. Wang X, Zingarelli B, O'Connor M, Zhang P, Adeyemo A, Kranias EG, Wang Y, Fan GC: Overexpression of Hsp20 prevents endotoxininduced myocardial dysfunction and apoptosis via inhibition of NFkappaB activation. J Mol Cell Cardiol 2009, 47:382-390

4. Fujita M, Kuwano K, Kunitake R, Hagimoto N, Miyazaki H, Kaneko Y, Kawasaki M, Maeyama T, Hara N: Endothelial cell apoptosis in lipopolysaccharide-induced lung injury in mice. Int Arch Allergy Immunol 1998, 117:202-208

5. Haimovitz-Friedman A, Cordon-Cardo C, Bayoumy S, Garzotto M, McLoughlin M, Gallily R, Edwards CK 3rd, Schuchman EH, Fuks Z, Kolesnick R: Lipopolysaccharide induces disseminated endothelia apoptosis requiring ceramide generation. J Exp Med 1997, 186: 1831-1841

6. Hickson-Bick DL, Jones C, Buja LM: Stimulation of mitochondrial biogenesis and autophagy by lipopolysaccharide in the neonatal rat cardiomyocyte protects against programmed cell death. $\mathrm{J}$ Mol Cell Cardiol 2008, 44:411-418

7. Meng N, Wu L, Gao J, Zhao J, Su L, Su H, Zhang S, Miao J: Lipopolysaccharide induces autophagy through BIRC2 in human umbilical vein endothelial cells. J Cell Physiol 2010, 225:174-179

8. Wang K, Damjanov I, Wan YJ: The protective role of pregnane $X$ receptor in lipopolysaccharide/D-galactosamine-induced acute liver injury. Lab Invest 2010, 90:257-265

9. Carchman EH, Rao J, Loughran PA, Rosengart MR, Zuckerbraun BS: Heme oxygenase-1-mediated autophagy protects against hepatocyte cell death and hepatic injury from infection/sepsis in mice. Hepatology 2011, 53:2053-2062

10. Xie Z, Klionsky DJ: Autophagosome formation: core machinery and adaptations. Nat Cell Biol 2007, 9:1102-1109

11. Ohsumi Y: Molecular dissection of autophagy: two ubiquitin-like systems. Nat Rev Mol Cell Biol 2001, 2:211-216

12. Suzuki K, Kirisako T, Kamada Y, Mizushima N, Noda T, Ohsumi Y: The pre-autophagosomal structure organized by concerted functions of APG genes is essential for autophagosome formation. EMBO J 2001 , 20:5971-5981

13. Boya P, Gonzalez-Polo RA, Casares N, Perfettini JL, Dessen P, Larochette N, Metivier D, Meley D, Souquere S, Yoshimori T, Pierron G,
Codogno P, Kroemer G: Inhibition of macroautophagy triggers apoptosis. Mol Cell Biol 2005, 25:1025-1040

14. Ishida Y, Nagata K: Autophagy eliminates a specific species of misfolded procollagen and plays a protective role in cell survival against ER stress. Autophagy 2009, 5:1217-1219

15. Scherz-Shouval R, Weidberg H, Gonen C, Wilder S, Elazar Z, Oren M: p53-dependent regulation of autophagy protein LC3 supports cancer cell survival under prolonged starvation. Proc Natl Acad Sci U S A 2010, 107:18511-18516

16. Li J, Hou N, Faried A, Tsutsumi S, Takeuchi T, Kuwano H: Inhibition of autophagy by 3-MA enhances the effect of 5-FU-induced apoptosis in colon cancer cells. Ann Surg Oncol 2009, 16:761-771

17. Periyasamy-Thandavan S, Jiang M, Wei Q, Smith R, Yin XM, Dong Z: Autophagy is cytoprotective during cisplatin injury of renal proximal tubular cells. Kidney Int 2008, 74:631-640

18. Jiang M, Liu K, Luo J, Dong Z: Autophagy is a renoprotective mechanism during in vitro hypoxia and in vivo ischemia-reperfusion injury, Am J Pathol 2010, 176:1181-1192

19. Yang PM, Liu YL, Lin YC, Shun CT, Wu MS, Chen CC: Inhibition of autophagy enhances anticancer effects of atorvastatin in digestive malignancies. Cancer Res 2010, 70:7699-7709

20. Degenhardt K, Mathew R, Beaudoin B, Bray K, Anderson D, Chen G Mukherjee C, Shi Y, Gelinas C, Fan Y, Nelson DA, Jin S, White E: Autophagy promotes tumor cell survival and restricts necrosis, inflammation, and tumorigenesis. Cancer Cell 2006, 10:51-64

21. Li F, Mao HP, Ruchalski KL, Wang YH, Choy W, Schwartz JH, Borkan SC: Heat stress prevents mitochondrial injury in ATP-depleted renal epithelial cells. Am J Physiol Cell Physiol 2002, 283:C917-C926

22. Beere HM, Wolf BB, Cain K, Mosser DD, Mahboubi A, Kuwana T, Tailor P, Morimoto RI, Cohen GM, Green DR: Heat-shock protein 70 inhibits apoptosis by preventing recruitment of procaspase-9 to the Apaf-1 apoptosome. Nat Cell Biol 2000, 2:469-475

23. Gabai VL, Yaglom JA, Volloch V, Meriin AB, Force T, Koutroumanis M, Massie B, Mosser DD, Sherman MY: Hsp72-mediated suppression of c-Jun N-terminal kinase is implicated in development of tolerance to caspase-independent cell death. Mol Cell Biol 2000, 20:6826-6836

24. Bidmon $\mathrm{B}$, Endemann $\mathrm{M}$, Arbeiter $\mathrm{K}$, Ruffingshofer $\mathrm{D}$, Regele $\mathrm{H}$, Herkner K, Eickelberg O, Aufricht C: Overexpression of HSP-72 confers cytoprotection in experimental peritoneal dialysis. Kidney Int 2004, 66:2300-2307

25. Zhou Y, Mao H, Li S, Cao S, Li Z, Zhuang S, Fan J, Dong X, Borkan SC, Wang Y, Yu X: HSP72 inhibits Smad3 activation and nuclear translocation in renal epithelial-to-mesenchymal transition. J Am Soc Nephrol 2010, 21:598-609

26. Mao H, Wang Y, Li Z, Ruchalski KL, Yu X, Schwartz JH, Borkan SC: Hsp72 interacts with paxillin and facilitates the reassembly of focal adhesions during recovery from ATP depletion. J Biol Chem 2004, 279:15472-15480

27. Rougier JP, Moullier P, Piedagnel R, Ronco PM: Hyperosmolality suppresses but TGF beta 1 increases MMP9 in human peritoneal mesothelial cells. Kidney Int 1997, 51:337-347

28. Rampino T, Cancarini G, Gregorini M, Guallini P, Maggio M, Ranghino A, Soccio G, Dal Canton A: Hepatocyte growth factor/scatter factor released during peritonitis is active on mesothelial cells. Am J Pathol 2001, 159:1275-1285

29. Zhu F, Li T, Qiu F, Fan J, Zhou Q, Ding X, Nie J, Yu X: Preventive effect of Notch signaling inhibition by a gamma-secretase inhibitor on peritoneal dialysis fluid-induced peritoneal fibrosis in rats. Am J Pathol 2010, 176:650-659

30. Nie J, Dou X, Hao W, Wang X, Peng W, Jia Z, Chen W, Li X, Luo N, Lan HY, Yu XQ: Smad7 gene transfer inhibits peritoneal fibrosis. Kidney Int 2007, 72:1336-1344

31. Mao H, Li Z, Zhou Y, Li Z, Zhuang S, An X, Zhang B, Chen W, Nie J, Wang Z, Borkan SC, Wang Y, Yu X: HSP72 attenuates renal tubular cell apoptosis and interstitial fibrosis in obstructive nephropathy. Am J Physiol Renal Physiol 2008, 295:F202-F214

32. Leu TH, Charoenfuprasert S, Yen CK, Fan CW, Maa MC: Lipopolysaccharide-induced c-Src expression plays a role in nitric oxide and TNFalpha secretion in macrophages. Mol Immunol 2006, 43:308-316

33. Song SH, Kwak IS, Yang BY, Lee DW, Lee SB, Lee MY: Role of rosiglitazone in lipopolysaccharide-induced peritonitis: a rat peritoneal dialysis model. Nephrology (Carlton) 2009, 14:155-163

34. Suzuki S, Maruyama S, Sato W, Morita Y, Sato F, Miki Y, Kato S, Katsuno M, Sobue G, Yuzawa Y, Matsuo S: Geranylgeranylacetone 
ameliorates ischemic acute renal failure via induction of Hsp70. Kidney Int 2005, 67:2210-2220

35. Maiuri MC, Zalckvar E, Kimchi A, Kroemer G: Self-eating and selfkilling: crosstalk between autophagy and apoptosis. Nat Rev Mol Cell Biol 2007, 8:741-752

36. Levine B, Yuan J: Autophagy in cell death: an innocent convict? J Clin Invest 2005, 115:2679-2688

37. Kabeya $Y$, Mizushima N, Ueno T, Yamamoto A, Kirisako T, Noda T, Kominami E, Ohsumi Y, Yoshimori T: LC3, a mammalian homologue of yeast Apg8p, is localized in autophagosome membranes after processing. EMBO J 2000, 19:5720-5728

38. Yang Z, Klionsky DJ: Eaten alive: a history of macroautophagy, Nat Cell Biol 12:814-822

39. Takahashi K, Naito M, Umeda S, Shultz LD: The role of macrophage colony-stimulating factor in hepatic glucan-induced granuloma formation in the osteopetrosis mutant mouse defective in the production of macrophage colony-stimulating factor. Am J Pathol 1994, 144: 1381-1392

40. Li HL, Suzuki J, Bayna E, Zhang FM, Dalle Molle E, Clark A, Engler RL, Lew WY: Lipopolysaccharide induces apoptosis in adult rat ventricular myocytes via cardiac AT(1) receptors. Am J Physiol Heart Circ Physiol 2002, 283:H461-467

41. Lieberthal W: Macroautophagy: a mechanism for mediating cell death or for promoting cell survival? Kidney Int 2008, 74:555-557

42. Wang Y, Singh R, Massey AC, Kane SS, Kaushik S, Grant T, Xiang Y, Cuervo AM, Czaja MJ: Loss of macroautophagy promotes or prevents fibroblast apoptosis depending on the death stimulus. J Biol Chem 2008, 283:4766-4777

43. Gupta S, Deepti A, Deegan S, Lisbona F, Hetz C, Samali A: HSP72 protects cells from ER stress-induced apoptosis via enhancement of IRE1alpha-XBP1 signaling through a physical interaction. PLOS Biol 2010, 8:e1000410

44. Li DD, Wang LL, Deng R, Tang J, Shen Y, Guo JF, Wang Y, Xia LP, Feng GK, Liu QQ, Huang WL, Zeng YX, Zhu XF: The pivotal role of c-Jun NH2-terminal kinase-mediated Beclin 1 expression during anticancer agents-induced autophagy in cancer cells. Oncogene 2009, 28:886-898

45. Ren H, Fu K, Mu C, Li B, Wang D, Wang G: DJ-1, a cancer and Parkinson's disease associated protein, regulates autophagy through JNK pathway in cancer cells. Cancer Lett 2010, 297:101-108

46. Cui Q, Tashiro S, Onodera S, Minami M, Ikejima T: Oridonin induced autophagy in human cervical carcinoma HeLa cells through Ras. JNK, and P38 regulation. J Pharmacol Sci 2007, 105:317-325

47. Ishii $Y$, Kwong JM, Caprioli J: Retinal ganglion cell protection with geranylgeranylacetone, a heat shock protein inducer, in a rat glaucoma model. Invest Ophthalmol Vis Sci 2003, 44:1982-1992

48. Xu Y, Kim SO, Li Y, Han J: Autophagy contributes to caspaseindependent macrophage cell death. J Biol Chem 2006, 281:19179 19187

49. Hofius D, Schultz-Larsen T, Joensen J, Tsitsigiannis DI, Petersen NH, Mattsson O, Jorgensen LB, Jones JD, Mundy J, Petersen M: Au- tophagic components contribute to hypersensitive cell death in Arabidopsis. Cell 2009, 137:773-783

50. Veneault-Fourrey C, Barooah M, Egan M, Wakley G, Talbot NJ: Autophagic fungal cell death is necessary for infection by the rice blast fungus. Science 2006, 312:580-583

51. Colell A, Ricci JE, Tait S, Milasta S, Maurer U, Bouchier-Hayes L, Fitzgerald P, Guio-Carrion A, Waterhouse NJ, Li CW, Mari B, Barbry P, Newmeyer DD, Beere HM, Green DR: GAPDH and autophagy preserve survival after apoptotic cytochrome $c$ release in the $a b-$ sence of caspase activation. Cell 2007, 129:983-997

52. Wu YT, Tan HL, Huang Q, Kim YS, Pan N, Ong WY, Liu ZG, Ong CN, Shen HM: Autophagy plays a protective role during ZVAD-induced necrotic cell death. Autophagy 2008, 4:457-466

53. James $P$, Pfund $C$, Craig EA: Functional specificity among Hsp70 molecular chaperones. Science 1997, 275:387-389

54. Guzhova I, Margulis B: Hsp70 chaperone as a survival factor in cell pathology. Int Rev Cytol 2006, 254:101-149

55. Zhao Y, Wang W, Qian L: Hsp70 may protect cardiomyocytes from stress-induced injury by inhibiting Fas-mediated apoptosis. Cell Stress Chaperones 2007, 12:83-95

56. Yang Q, She H, Gearing M, Colla E, Lee M, Shacka JJ, Mao Z: Regulation of neuronal survival factor MEF2D by chaperone-mediated autophagy. Science 2009, 323:124-127

57. Dice JF: Chaperone-mediated autophagy. Autophagy 2007, 3:295299

58. Hirsh MI, Hashiguchi N, Chen Y, Yip L, Junger WG: Surface expression of HSP72 by LPS-stimulated neutrophils facilitates gammadeltaT cell-mediated killing. Eur J Immunol 2006, 36:712-721

59. Tang D, Kang R, Xiao W, Wang H, Calderwood SK, Xiao X: The anti-inflammatory effects of heat shock protein 72 involve inhibition of high-mobility-group box 1 release and proinflammatory function in macrophages. J Immunol 2007, 179:1236-1244

60. Wei Y, Pattingre S, Sinha S, Bassik M, Levine B: JNK1-mediated phosphorylation of $\mathrm{Bcl}-2$ regulates starvation-induced autophagy. Mol Cell 2008, 30:678-688

61. Li C, Capan E, Zhao Y, Zhao J, Stolz D, Watkins SC, Jin S, Lu B: Autophagy is induced in CD4+ T cells and important for the growth factor-withdrawal cell death. J Immunol 2006, 177:5163-5168

62. Borsello T, Croquelois K, Hornung JP, Clarke PG: N-methyl-d-aspartate-triggered neuronal death in organotypic hippocampal cultures is endocytic, autophagic and mediated by the c-Jun $\mathrm{N}$-terminal kinase pathway. Eur J Neurosci 2003, 18:473-485

63. Jia G, Cheng G, Gangahar DM, Agrawal DK: Insulin-like growth factor-1 and TNF-alpha regulate autophagy through c-jun N-terminal kinase and Akt pathways in human atherosclerotic vascular smooth cells. Immunol Cell Biol 2006, 84:448-454

64. Park KJ, Lee SH, Lee CH, Jang JY, Chung J, Kwon MH, Kim YS: Upregulation of Beclin-1 expression and phosphorylation of $\mathrm{Bcl}-2$ and p53 are involved in the JNK-mediated autophagic cell death. Biochem Biophys Res Commun 2009, 382:726-729 